\title{
Protective Effects of $N$. sativa against the Adverse Effects of Aflatoxicosis in Ducklings
}

\author{
S. K. L. Karna \\ Trichandra Multipul Campus, Tribhuvan University, Ghantaghar, Kathmandu \\ e-mail:skkkth@yahoo.com
}

\begin{abstract}
Aflatoxin produced by Aspergillus flavus toxigenic strain was selected as a potent and widely distributed hepatotoxin that induces much health and economic hazards in animals and humans. A. flavus was cultivated on rice to produce the aflatoxin used in the present study. It was aimed to study the adverse effects of aflatoxin on some biochemical parameters in serum and liver of ducklings as well as to evaluate the possible protective effects of $N$.sativa crushed seeds against the adverse effects of this. Total proteins, albumin, globulins, alanine aminotransferase (ALT) (EC 2.6.1.1) and aspartate aminotransferase (AST) (EC 2.6.1.2), cholesterol and triacylglycerols were measured in the serum of the test animal. The levels of hepatic malondialdhyde and glutathione level, glutathione S-transferase (GST) (EC: 2.5.1.18) activity, aflatoxin residues and histopathological changes were also measured. The obtained results suggest that the addition of $N$. sativa to duckling's ration has a protective effect against aflatoxicosis. The result concluded that aflatoxin had hepatotoxic effects through decrease of total proteins, albumin, glutathione and glutathione S-transferase. In addition, aflatoxin induced histopathological changes of liver of the test animal and residues of aflatoxin were measured. So, we advice to use $N$. sativa as a feed additive for controlling aflatoxicosis in poultry farms.
\end{abstract}

Key words:Aspergillus flavus, aflatoxin, N.sativa, antioxidant, hepatoprotection

\section{Introduction}

Aflatoxins (AF) are produced by Aspergillu flavus, A. parasiticus, A. nomiusand A.and pseudotamariias as secondary metabolites (CAST 2003).Since their discovery in the 1960s, AF have been demonstrated to be carcinogenic in many animal species, including rodents, non-human primates and fish. They have been also suspected to induce to human hepatocellular carcinoma, in addition, many species, including rat, turkey, duck, trout, and primates, are susceptible to the carcinogenic effects of AFB. (Jackson 1999). Corn and peanut showed that $\mathrm{AFB}_{1}$ contamination to be higher than 50\% in Egypt (Donmat 2007) N. sativa and its oil is being used as food additives as well as natural remedies for many ailments for over thousands of years. Many active ingredients have been isolated from this plant, including thymoquinone, thymohydroquinone, dithymo-quinone, thymol, carvacrol, nigellicine and alpha-hedrin which have been identified such as antitumour activity, antioxidant activity, antiinflammatory activity, antibacterial activity and immunostimulant (Salem 2000). The seeds have been used as a natural remedy for more than 2000 years to promote health and treatment of diseases of animals. Medicinal properties of black seeds have even been mentioned by the Prophet of Islam, Muhammad and its use was recommended for various ailments (Bhati 2009).

\section{Methodology}

The present study was carried out on 100 Pekin ducklings each weighing $200 \mathrm{~g}$ at (Hetauda Farm, Makawanpur) with an average body weight of (200 g). They were given basal diet and water ad libitum and housed in the same place for two weeks before commencing the experiment for acclimatization and to ensure a normal growth and behavior.

Medical plants and Aspergillus flavus strain N.sativa seeds were obtained from the Department of Botany, Trichandra Campus, Tribhuvan University, Kathmandu, purified and, finally ground in mortar and 
added to the diet as discribed below $A$. flavus toxigenic strain was used for the in vitro experiment.

\section{Diet}

Basal diet of the ducklings included (63.1\% ground yellow corn, $28.2 \%$ soya bean meal, $4.3 \%$ corn gluten meal, $0.6 \%$ vegetable oils, $1.8 \%$ dicalcium phosphate, $1.1 \%$ ground limestone, $0.4 \%$ common salts, $0.3 \%$ mineral and vitamin premix, $0.1 \%$ lysine and $0.1 \%$ methionine).

\section{In vitro experiment}

\section{Aflatoxin production on corn}

A. flavus isolates were kept in physiological salt solution containing $0.01 \%$ Tween 80 (PST); They were inoculated onto Czapek'sDox plates and incubated at $30^{\circ} \mathrm{C}$ for 7 days. After this period, the spores were harvested by washing the Czapek'sDox surface with sterile PST. The harvested spores were enumerated and used as inoculums of $\left(5 \times 10^{3} / \mathrm{ml}\right)$ spore count (Criseo 2001). A. flavus strain was inoculated on corn flasks (triplicate for each treatment) according to the method of (shotwell 1966) with some modifications as the following: $50 \mathrm{~g}$ of yellow corn and A. flavus inoculums $\left(\mathrm{T}_{1}\right), 50 \mathrm{~g}$ of yellow corn, A. flavus inoculums and N.sativa crushed seeds $0.5 \%\left(\mathrm{~T}_{2}\right) ; 50 \mathrm{~g}$ of yellow corn, A. flavus inoculums and $N$. sativa crushedseeds $1.0 \%\left(\mathrm{~T}_{3}\right)$ and $50 \mathrm{~g}$ of yellow corn, $A$. flavus inoculums and $N$. sativa crushed seeds $2.0 \%\left(\mathrm{~T}_{4}\right)$.

\section{Aflatoxin extraction and quantification}

Residues of $\mathrm{AFB}_{1}, \mathrm{AFB}_{2}$ in corn were determined using the method of Association of Official Analytical Chemists (AOAC 1995) with the same modifications. Then the extracted aflatoxins were measured by high performance liquid chromatography (HPLC).

\section{Aflatoxin production on rice for in vivo experiment}

A. flavus (spores) was cultured on rice for production of aflatoxin which was used for in vivo experiment by the method of (Showell 1996). Rice was collected, dried, grinded and subjected to extraction of aflatoxin which then was measured by HPLC. The extracted aflatoxin was dissolved in corn oil by using chloroform then adding to the corn oil with continuous mixing by magnetic stirrer at $60^{\circ} \mathrm{C}$ to evaporate chloroform leaving aflatoxin mixed with corn oil.

\section{In vivo experiment}

Hundred ducklings were allotted into two equal groups Group ${ }^{1}$ was fed with basal diet with corn oil orally and Group ${ }^{2}$ was fed on basal diet with corn oil containing aflatoxin ( $30 \mu \mathrm{g} / \mathrm{kg} /$ duckling daily) orally for 2 weeks. After two weeks, five ducklings from each group were scarified. Blood and liver samples of these birds were collected for biochemical analysis and histopathological examination of liver. After withdrawal of aflatoxin the remaining birds of each group were allotted into two subgroups. The experimental design will become as the following; Control (Group ${ }^{3}$ ) consists of 20 ducklings were fed a basal diet; Group ${ }^{4}$ : consists of 25 ducklings were fed a basal diet containing crushed $N$.sativa seeds by a concentration of $2.0 \%$; Group ${ }^{5}$ : consists of 20 ducklings were fed a basal diet and Group $^{6}$ : consists of 20 ducklings were fed a basal diet containing crushed $N$. sativa seeds by a concentration of $2.0 \%$. Blood and liver samples were collected at $6^{\text {th }}$ and $8^{\text {th }}$ weeks after aflatoxin withdrawal.

\section{Blood and liver samples}

At $6^{\text {th }}$ ( 2 weeks after AF withdrawal) and $8^{\text {th }}$ week (4 weeks after AF withdrawal) blood samples from each group were collected by animal scarification and centrifuged at $3000 \mathrm{rpm}$ for $10 \mathrm{~min}$. Separated sera were collected in eppindorff tubes and kept at $-20^{\circ} \mathrm{C}$ until biochemical analysis was done. After the ducklings were scarified, the abdomens were immediately opened and the liver removed and divided into three parts: the first part was kept at $-20^{\circ} \mathrm{C}$ for biochemical measurements. The second part was kept at $-20^{\circ} \mathrm{C}$ for extraction and quantificatation of aflatoxin residues and the last part was collected in $10 \%$ neutral buffered formalin solution (BFS) for histopathology.

\section{Biochemical analysis of serum and liver}

Serum samples were subjected to biochemical analysis for serum total proteins and albumin (Henry 1964), serum globulins (Coles 1974), ALT (EC 2.6.1.1) and AST (EC 2.6.1.2) (Reitman 1957), cholesterol (Zak 1954) and triacylglycerols ( Fossati 1982). Liver samples were used for measurement of malondialdhyde (MDA) (Placer 1966), Glutathione ( Sedlak 1968) and Glutathione S-transferase (GST) (EC: 2.5.1.18) activity(Hebig 1974). Residues of aflatoxin in liver samples of all groups before and after withdrawal of aflatoxin were determined by the method of (AOAC 1995). 


\section{Histopathological studies}

Liver specimen were collected and rapidly fixed in $10 \%$ BFS for at least 24 hours. The fixed specimens were processed through the conventional paraffin embedding technique (dehydration through ascending grades of ethanol, clearing in chloroform and embedding in paraffin wax at $60^{\circ} \mathrm{C}$. Paraffin blocks were prepared from which 5 microns thick sections were obtained and stained by Hematoxyline and Eosin (H\&E) according to the method described by ( Culling 1983).

\section{Results and Discussion}

\section{In vitro experiment}

Addition of N.sativa to yellow corn by concentrations of $0.5 \%, 1.0 \%$, and $2.0 \%$ were decreased the $\mathrm{AFB}_{1}$ production levels significantly with inhibition percentages of $14.75 \%, 27.95 \%, 57.55 \%$, respectively when compared with control positive group (Table 1). At the same concentrations $\mathrm{AFB}_{2}$ production were inhibited by percentages of $7.14 \%, 12.96 \%$, and $72.22 \%$, respectively. Aflatoxin production by in vitro study indicated that $N$. sativa crushed seeds have an inhibitory effect on growth and aflatoxin production by Aspergillus flavus. Results from this experiment were come in accordance with studies of the antifungal effects of thymoquinone (AL- Quarashi 2007) against A.flavus. N.sativa oilcompletely inhibited aflatoxin production by A.flavus at $3 \%(\mathrm{v} / \mathrm{v})$ concentration, while crude extract of N.sativa inhibited three types of aflatoxins at $5 \%(\mathrm{w} / \mathrm{v})$ concentration. The inhibitory effect of N.sativa on aflatoxin production ability of A.flavus might be related to several components known to have biological activities, such as á-pinene and thymol and high phenolic content (Maraqa 2007).

Table 1. Effect of $N$. Sativa on aflatoxin production from Aspergillus flavus

\begin{tabular}{c|c|c|c|c}
\hline & $\begin{array}{c}\text { AFB1 } \\
\text { production level } \\
(\mathrm{ppb})\end{array}$ & $\begin{array}{c}\text { AFB1 } \\
\text { production } \\
\text { inhibition } \%\end{array}$ & $\begin{array}{c}\text { AFB2 } \\
\text { production level } \\
(\mathrm{ppb})\end{array}$ & $\begin{array}{c}\text { AFB2 } \\
\text { production } \\
\text { inhibition\% }\end{array}$ \\
\hline T1 & $1152 \pm 3.90$ & 14.75 & $54 \pm 1.25$ & 7.14 \\
T2 & $936 \pm 0.56 *$ & 27.95 & $50 \pm 0.24$ & 12.96 \\
T3 & $830 \pm 5.43^{*}$ & 57.55 & $15 \pm 0.28^{*}$ & 72.22 \\
T4 & $489 \pm 4.89^{*}$ & & $47 \pm 1.51$ & 7 \\
\hline
\end{tabular}

*Values are significant compared to control ( $\mathrm{P}<0.05$ ). $\mathrm{T}_{1}$ (control flasks); $\mathrm{T}_{2}$ (N.sativa 0.5\% and A. flavus); $\mathrm{T}_{3}$ (N.sativa $0.5 \%$ and $A$. flavus); $\mathrm{T}_{4}$ (N.sativa $0.5 \%$ and A. flavus).

\section{In vivo experiment}

Table, (2) revealed that in group2 the levels of serum total proteins and serum albumin were significantly decreased. On the other hand, the levels of ALT, AST, cholesterol and triacylglycerols were significantly increased in comparable to control group. The same results were obtained by the studies on broiler chicks (Toulah, 2007) Japanese quail ( Madheswaran 2004) and ducks (Han 2008). The decrease in total serum proteins might be contributed to the binding of aflatoxin to DNA. Therefore, aflatoxin hinder transcription and translation in return decreased the protein synthesis, as the exo-epoxide product of aflatoxin metabolism reacted with $\mathrm{N}_{7}$-guanine in DNA and contributed to protein adduct formation of aflatoxin (Cavin 2008).

Table 2. Effect of aflatoxin on total proteins, albumin, ALT, AST, cholesterol and triacylglycerols level

\begin{tabular}{c|c|c|c|c|c|l}
\hline & Total proteins & Albumin & ALT & AST & Cholesterol & Triacylglycerol \\
\hline Group1 & $7.54 \pm 0.22$ & $5.09 \pm 0.43$ & $17 \pm 0.07$ & $18 \pm 2.41$ & $120.6 \pm 6.25$ & $138.24 \pm 7.12$ \\
& $6.21 \pm 0.08 *$ & $3.79 \pm 0.07 *$ & $42 \pm 2.37 *$ & $48 \pm 1.46 *$ & $198 \pm 4.27 *$ & $172.04 \pm 8.40 *$ \\
\hline
\end{tabular}

* Values are significant as compared to control $(P<0.05)$. Group1 (Control); Group2 (Aflatoxin treated)

The data illustrated in Table 3. stated that at $6^{\text {th }}$ week of age the serum levels of total protein and albumin were significantly increased while cholesterol and triacylglycerol levels were significantly decreased in 
group4 in comparison to control one. Group5, serum total protein levels were significantly decreased. In contrary, levels of ALT, AST, cholesterol and triacylglycerol were significantly increased. In group6, all parameter levels were reverted near control levels except ALT enzyme activity. The data illustrated in Table 4 . revealed that at $8^{\text {th }}$ week total proteins and albumin levels were significantly increased, while cholesterol and triacylglycerol levels were significantly decreased in group4 in comparison with control one. In group5 cholesterol and triacylglycerol levels were significantly increased. In regard to group6 all tested parameters were nearly reverted around normal values this finding might be due to the antioxidant effect of N.sativa. These observations are agreed with that of [ AL-Gaby 1998] who used Nigella cake protein as feed supplement. N.sativa crushed seeds[ Le 2004) and thymoquinone (Badary 2000) were significantly decreased serum triacylglycerol level. This result might be due to the antioxidant effect of N.sativa against aflatoxin. On observed data in Table 5. revealed that, in group2 (2 weeks post-treatment) MDA level was increased significantly. While, glutathione levels and GST activities were significantly decreased in comparable to control one.After 2 and 4 weeks of withdrawal of aflatoxin ( $6^{\text {th }}$ and $8^{\text {th }}$ week) Table 6 . revealed a significantly decrease in MDA levels in group4 and a significant increase in group 5. But, hepatic glutathione levels were significantly increased in group4 and significantly decreased in group 5 than control. N.sativa significantly increased GST activity at $6^{\text {th }}$ week and $8^{\text {th }}$ week (group4). In contrary its activities were significantly decreased in group5 when compared with control. At $6^{\text {th }}$ week group6, GST activity has no differences but at $8^{\text {th }}$ week, its level was significantly increased.

Table 3. Effects of N.sativa on serum total proteins (g/dl), albumin (g/dl), ALT (U/L), AST (U/L), cholesterol (g/dl) and triacylglycerol (g/dl) two weeks after aflatoxin withdrawal

\begin{tabular}{c|c|c|c|c|c|c}
\hline & Total Proteins & Albumin & ALT & AST & Cholesterol & Triacylglycerol \\
\hline Group3 & $7.77 \pm 0.11$ & $4.28 \pm 0.01$ & $17 \pm 1.10$ & $22 \pm 1.40$ & $150.75 \pm 1.25$ & $130.64 \pm 2.01$ \\
Group4 & $8.85 \pm 0.03^{*}$ & $5.86 \pm 0.11^{*}$ & $16 \pm 0.97$ & $21 \pm 1.52$ & $129.80 \pm 2.14 *$ & $112.12 \pm 0.10^{*}$ \\
Group5 & $5.74 \pm 0.47^{*}$ & $3.08 \pm 0.14$ & $42 \pm 3.12^{*}$ & $46 \pm 3.41^{*}$ & $193.05 \pm 4.11^{*}$ & $166.01 \pm 0.14 *$ \\
Group6 & $7.19 \pm 0.78$ & $3.78 \pm 0.25$ & $30 \pm 2.41^{*}$ & $28 \pm 2.56$ & $166.41 \pm 3.48$ & $137.37 \pm 1.74$ \\
\hline
\end{tabular}

*Values are significant compared to control ( $\mathrm{P}<0.05)$. Group3 (Control untreated); Group4 (N.sativa); Group5 (Aflatoxicated birds); Group6 (AF+ N.sativa)

Table 4. Effects of N.sativa on serum total proteins (g/dl), albumin (g/dl), ALT (U/L), AST (U/L), cholesterol (g/dl) and triacylglycerol (g/dl) four weeks after aflatoxin withdrawal

\begin{tabular}{c|l|c|c|c|c|c}
\hline \multicolumn{7}{c}{ 8th week of age (4 weeks post-aflatoxin withdrawal) } \\
& Total & Albumin & ALT & AST & Cholesterol & Triacylglycerol \\
& proteins & & & & \\
\hline Group3 & $6.48 \pm 0.24$ & $4.25 \pm 0.74$ & $18 \pm 1.42$ & $21 \pm 0.88$ & $149.17 \pm 4.23$ & $131.13 \pm 3.12$ \\
Group4 & $8.61 \pm 0.22 *$ & $5.27 \pm 0.54 *$ & $15 \pm 2.40$ & $21 \pm 0.16$ & $121.45 \pm 1.47 *$ & $120.76 \pm 0.50^{*}$ \\
Group5 & $6.59 \pm 0.14$ & $4.07 \pm 0.47$ & $28 \pm 1.16$ & $31 \pm 1.33$ & $190.6 \pm 4.20^{*}$ & $158.78 \pm 4.79 *$ \\
Group6 & $7.38 \pm 0.81$ & $4.20 \pm 0.30$ & $22 \pm 0.78$ & $27 \pm 1.27$ & $138.6 \pm 5.10$ & $133.5 \pm 3.12$ \\
\hline
\end{tabular}

*Values are significant compared to control ( $\mathrm{P}<0.05)$. Group3 (Control untreated); Group4 (N.sativa); Group5 (Aflatoxicated birds); Group6 (AF+ N.sativa) 
S. K. L. Karna/Protective Effects of N. sativa.....

Table 5. Effect of aflatoxin on hepatic MDA(nM MDA/ $g$ wet liver) and glutathione ( $\mu \mathrm{M} / \mathrm{g}$ wet liver) levels and GST activity ( $\mathrm{mmol} / \mathrm{min} / \mathrm{g}$ wet liver) at 4 th weeks of age ( 2 weeks post-treatment)

\begin{tabular}{c|c|c|c}
\hline & MDA & GSH & GST \\
\hline Group1 & $150.54 \pm 15.31$ & $5.26 \pm 0.13$ & $13.9 \pm 2.41$ \\
Group2 & $283.09 \pm 23.46^{*}$ & $2.01 \pm 0.24^{*}$ & $6.45 \pm 1.50^{*}$ \\
\hline
\end{tabular}

* Values are significant compared to control $(\mathrm{P}<0.05)$. Group1 (Control); Group2 (Aflatoxin treated)

Table 6. Effects of $N$. sativa on MDA level (nM MDA / $g$ wet liver), glutathione level ( $\mu M$ / $g$ wet liver) and glutathione $\mathrm{S}$ - transferase activity ( $\mathrm{mmol} / \mathrm{min} / \mathrm{g}$ wet liver) after withdrawal of aflatoxin

\begin{tabular}{c|c|c|c|c|c|c}
\hline & \multicolumn{3}{|c|}{6 week } & \multicolumn{3}{c}{8 week } \\
\hline & MDA & GSH & GST & MDA & GSH & GST \\
Group3 & $146.43 \pm 1.12$ & $4.67 \pm 0.12$ & $9.73 \pm 1.03$ & $152.7 \pm 7.15$ & $4.82 \pm 0.14$ & $21.74 \pm 2.45$ \\
Group4 & $113.41 \pm 1.02^{*}$ & $9.79 \pm 0.02^{*}$ & $17.77 \pm 2.78^{*}$ & $95.04 \pm 5.40^{*}$ & $11.14 \pm 0.45^{*}$ & $39.33 \pm 4.01^{*}$ \\
Group5 & $226.15 \pm 0.11^{*}$ & $1.14 \pm 1.47^{*}$ & $6.14 \pm 2.14$ & $203.37 \pm 1.45^{*}$ & $2.69 \pm 0.25$ & $11.87 \pm 2.69 *$ \\
Group6 & $154.80 \pm 1.23$ & $6.17 \pm 0.25^{*}$ & $7.90 \pm 1.01$ & $138.80 \pm 0.45$ & $5.43 \pm 1.21^{*}$ & $24.33 \pm 1.51$ \\
\hline
\end{tabular}

*Values are significant compared to control ( $\mathrm{P}<0.05 \mathrm{Group} 3$ (Control untreated); Group4 (N.sativa); Group5 (Aflatoxicated birds); Group6 (AF+ N.sativa)

Aflatoxin treatment caused a significant increase in lipid peroxidation in liver of aflatoxin-treated mice (Choudhary 2005), rabbit’s liver (Guerre 1999) and plasma MDA of quail (Citil 2005). After 30 days of aflatoxin treatment in chicks, hepatic GSH levels and GST activities concentration were significantly decreased (Karaman 2010) this decrease is obtained by the oxidant effect of aflatoxin as a xenobiotic substance. N.sativa crushed seeds significantly increased the activity of hepatic GST and GSH concentration in rabbit's liver. In contrary, lipid peroxidation product (MDA) levels were significantly decreased (EL-Far 2003). Pretreatment with thymoquinone and N.sativa oil were induced a significant decrease in MDA level as compared with ischemic group (Hosseinzadeh 2007). The results tabulated in Table 7. showed that the level of $\mathrm{AFB}_{1}$ and $\mathrm{AFB}_{2}$ accumulation in duckling's liver of group2, in which aflatoxin $B_{1}$ and $B_{2}$ residues are $2.21 \mathrm{ppb}$ and 0.27 ppb respectively. In the group 5 aflatoxin $B_{1}$ residues were decreased to $0.69 \mathrm{ppb}$ and $0.24 \mathrm{ppb}$ than that of group2 at $6^{\text {th }}$ and $8^{\text {th }}$ weeks respectively. Also, the level of aflatoxin $B_{1}$ residues were decreased in group6 to became $0.21 \mathrm{ppb}$ at $6^{\text {th }}$ week and in non detected amount at $8^{\text {th }}$ week. In respect to $\mathrm{AFB}_{2}$ residues were become in non detectable level in the group 5 and group6 all over the experimental period. Administration of aflatoxin to ducklings led to accumulation of aflatoxin in liver (Table 7.) which extracted and measured by HPLC. A variety of domestic poultry species were fed with diets containing $3000 \mathrm{ng} / \mathrm{kg} \mathrm{AFB}_{1}$ for a 7 day period and showed that levels of $\mathrm{AFB}_{1}$ and its metabolites were greater in liver than in muscle for all bird species tested (Bintvihok 2002). The highest levels of $\mathrm{AFB}_{1}$ residues were found in the liver, followed by the crop and muscle tissue (Madden 1995). AFB $_{1}$ residues were observed only in muscle and liver of birds given dietary AFB $_{1}$ (Bintvihok 2006). While, in group6 supplementation of ducklings by N.sativa crushed seeds decreased the residues of aflatoxin until $6^{\text {th }}$ week and this decreased continued until the level of aflatoxin in liver became in non-detectable level at $8^{\text {th }}$ week. This protective effect of N.sativa might be return to the antioxidant effect of N.sativa. 
Nepal Journal of Science and Technology Vol. 14, No. 2 (2013) 81-90

Table 7. AFB1 and AFB2 residues of duckling's liver before and after aflatoxin withdrawal

\begin{tabular}{|c|c|c|c|c|c|c|c|}
\hline & \multicolumn{2}{|c|}{$4^{\text {th }}$ week } & & \multicolumn{2}{|c|}{$6^{\text {th }}$ week } & \multicolumn{2}{|c|}{$8^{\text {th }}$ week } \\
\hline & AFB1 & AFB2 & & AFB1 & AFB2 & AFB1 & AFB2 \\
\hline \multirow{2}{*}{ Group1 } & \multirow{2}{*}{ ND } & \multirow{2}{*}{ ND } & Group3 & ND & ND & ND & ND \\
\hline & & & Group4 & ND & ND & ND & ND \\
\hline \multirow{2}{*}{ Group2 } & \multirow{2}{*}{$2.21 \mathrm{ppb}$} & \multirow{2}{*}{$0.27 \mathrm{ppb}$} & Group5 & $0.69 \mathrm{ppb}$ & ND & $0.24 \mathrm{ppb}$ & ND \\
\hline & & & Group6 & $0.21 \mathrm{ppb}$ & ND & ND & ND \\
\hline
\end{tabular}

*Values are significant compared to control (P<0.05). Group1 (Control); Group2 (Aflatoxin treated); Group3 (Control untreated); Group4 (N.sativa); Group5 (Aflatoxicated birds); Group6 (AF+ N.sativa); ND (Non detectable level)

\section{Histopathological studies}

Fig.1 showed normal healthy hepatocytes of control (group1). While, Fig. 2 showed diffuse hydropic degeneration due to oral administration of aflatoxin for two weeks.Histopathologically, in group 4 at $6^{\text {th }}$ week Fig.3 showed normal healthy hepatocytes. While at $8^{\text {th }}$ week after aflatoxin withdrawal, N.sativa succeeded to induce an activation of lymphoid aggregation in liver (Fig.4). Fig.5 showed the liver of ducklings in the group 5 at $6^{\text {th }}$ week after withdrawal of aflatoxin showing diffuse hydropic degeneration. While a degenerative changes in the hepatocytes with granular cytoplasm were noticed at $8^{\text {th }}$ week (Fig. 6) .Fig. 7 cleared that; addition of N.sativa in group 6 at $6^{\text {th }}$ week induced a focal infiltration of inflammatory cells besides mild hydropic degeneration. While addition of N.sativa ( $8^{\text {th }}$ week) induced a complete regeneration of the hepatic parenchyma (Fig. 8). Oral administration of

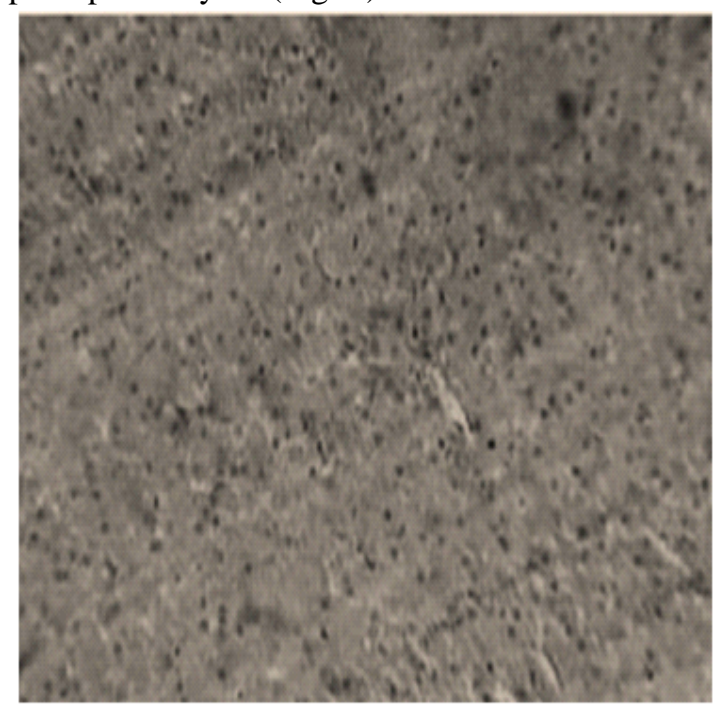

Fig. 1. liver of duck in group1 (control) showing normal and healthy hepatocytes. H\&E (X250) aflatoxin for two weeks induced liver injuries including diffuse hydropic degeneration. The microscopic changes including diffuse degeneration in parenchymal cells, enlarged nuclei and extensive bile duct proliferation was the most common acute toxicity of aflatoxin in chicken and ducklings livers respectively (Bintvihok 1991). In addition, aflatoxin induced a liver injury of ducklings such as bile duct proliferation and fatty degeneration (Abdolamin 2005). Poultry diets containing $2.0 \%$ N.sativa crushed seed is too useful to birds. Histologically, N.sativa induced an activation of lymphoid aggregation in liver at $6^{\text {th }}$ week ended by complete regeneration of liver at $8^{\text {th }}$ week. A marked increase in the number of mucus-secreting goblet cells in the airway mucosa, blocking of lung tissue eosinophilia and goblet cell hyperplasia were induced by thymoquinone (EL-Gazzar 2006).

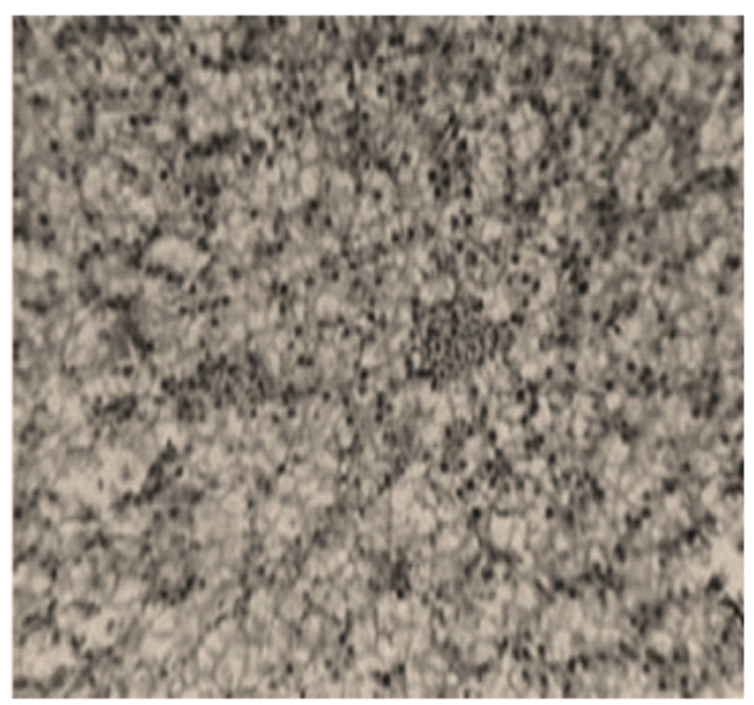

Fig. 2. liver of duck exposed to aflatoxin (group2) for two weeks showing diffused hydropic degeneration. H\&E (X250) 


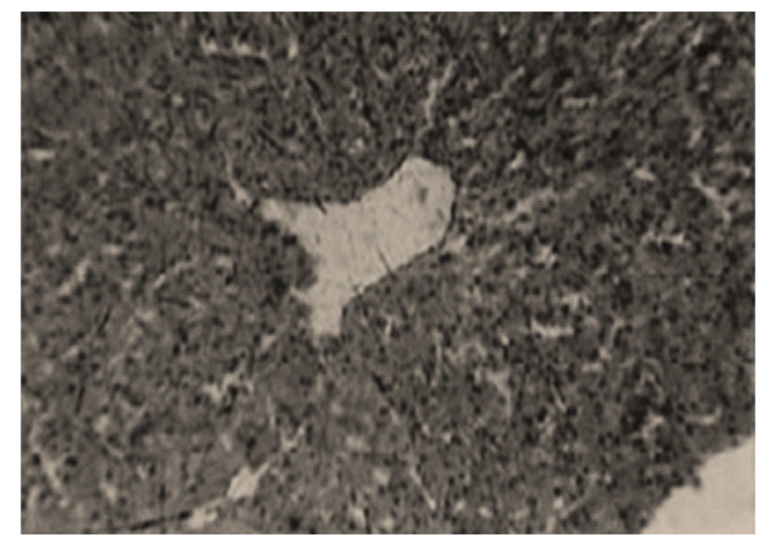

Fig. 3. liver of ducklings in $N$. sativa at 6 th week after withdrawal of aflatoxin showing normal hepatocytes. (H\&E (X 250)

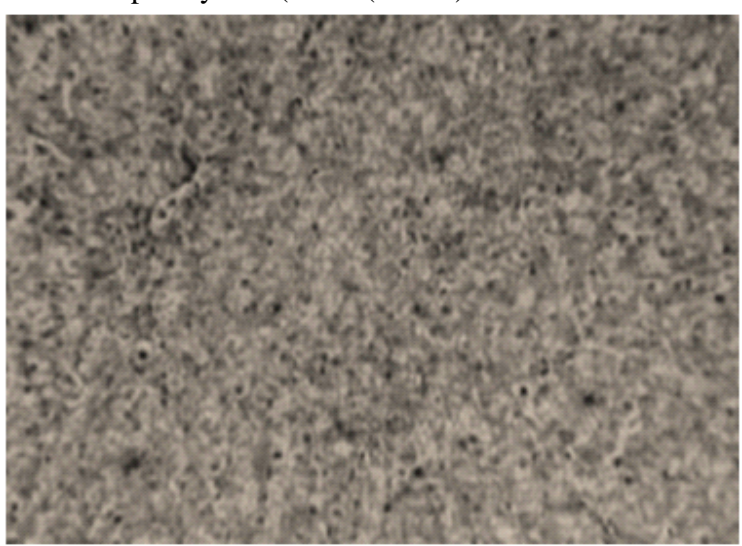

Fig. 5. liver of ducklings in the group 5 at 6 th week after withdrawal of aflatoxin showing diffuse hydropic degeneration H\&E (X 250)

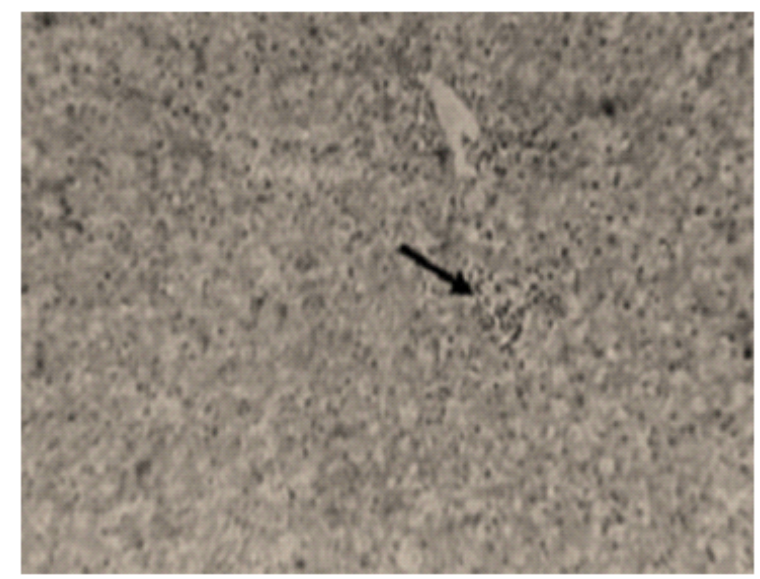

Fig. 7. liver of ducklings in the group6 at 6 Th week after withdrawal of aflatoxin showing focal infiltration of inflammatory cells (arrow) beside mild hydropic degeneration H\&E (X 250)

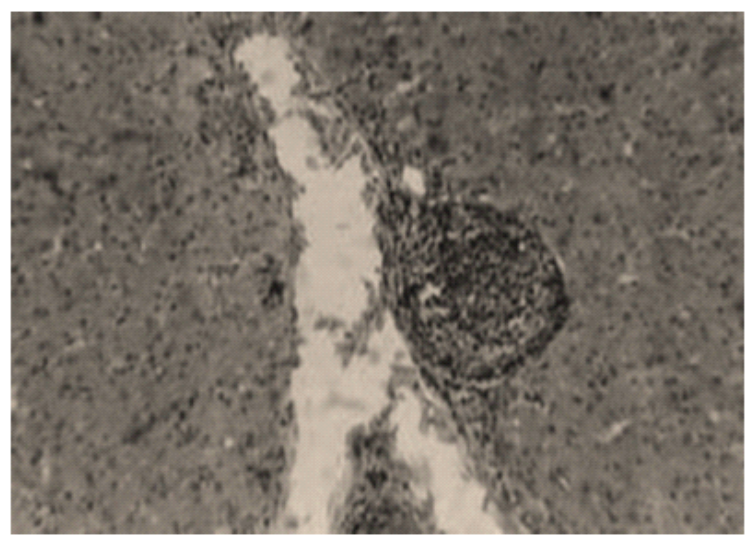

Fig. 4. liver of ducklings $N$. sativa $8^{\text {th }}$ week after withdrawal of aflatoxin showing an activation of lymphoid aggregation (H\&E (X 250)

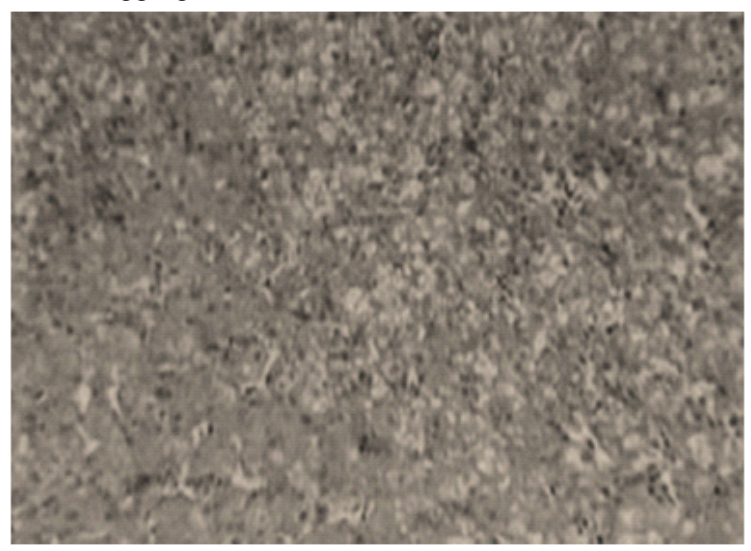

Fig. 6. liver of ducklings in the group5 at 8 th week after withdrawal of aflatoxin showing degenerative changes in the hepatocytes with granular cytoplasm $\mathrm{H} \& \mathrm{E}$ (X 250)

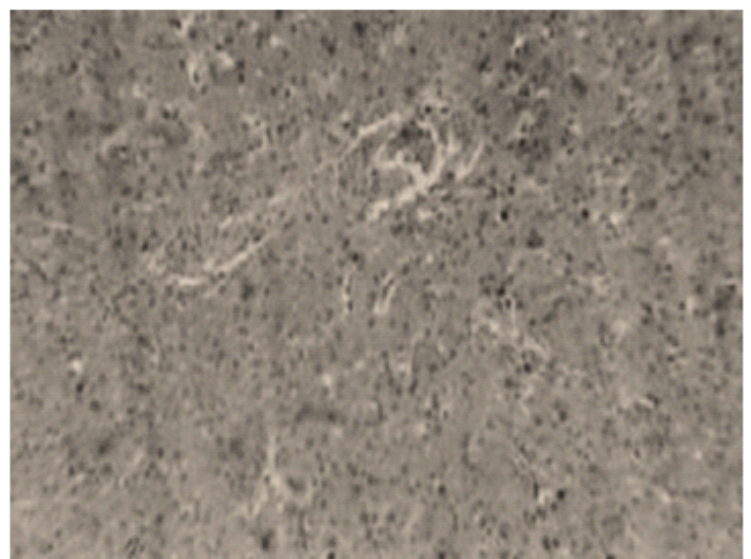

Fig. 8. liver of ducklings in the group6 at 8 th week after withdrawal of aflatoxin showing a complete regeneration of the hepatic parenchyma $\mathrm{H} \& \mathrm{E}$ (X 250) 
From the obtained results, it can be concluded that the addition of N.sativa as a feed additive in poultry diet products the hepatotoxicity induced by aflatoxin as N.sativa inhibit the growth and aflatoxin production by Aspergillus flavus.

\section{Acknowledgements}

My thanks are extended to Dr Ram Narayan Jha, Prof. of Chemistry, Trichandra Campus, Kathmandu, instrumentation and Histological section of Banaras HinduUniversity, India, Dr. Dil Bahadur Gurung, Executive Director of National Agriculture Research Council (NARC) and Mr. Binod Joshi, Hetauda Duck Makwanpur farm, for their sincere cooperation, throughout the study.

\section{References}

Abdolamir, A., S. Alireza, A.Seyed, S. Mahmmoud, R. Mehdi, and A. Azam, 2005. Evaluation of biochemical and production parameters of broiler chicks fed ammonia treated aflatoxin contaminated maize grains. Animal Feed Science and Technology 122 (3-4): 289-301.

Al-Gaby, A. M, 1998. Amino acid composition and biological effect of supplementing broad bean and corn protein with Nigella sativa (Black cumin) cake protein. Nahrung 42 (5): 290-294.

Al-Qurashi, A., A. Naeem, S. Al-Jabre, O. AL-Akloby and M. A. Randhawa. 2007. Anti-Fungal Activity of Thymoquinone and Amphotericine $\mathrm{B}$ against Aspergillus niger .Scientific Journal of King Faisal University (Basic and Applied Sciences) 8(1): 1428H.

AOAC (Association of Official Analytical Chemists),Official Methods of Analysis, 1966. Natural Toxins, vol. 2, $16^{\text {th }}$ ed. Association of Official Analytical Chemists, Gaithersburg.

Badary, O., A. Ashraf, B. Mohamed, H. Abdel-Wahab and M. A. Farid. 2000. The influence of thymoquinone on doxorubicin-induced hyperlipidemic nephropathy in rats. Toxicology. 143 (3): 219-226.

Bhatti, I.; Rehman, F.; M. Khan, and S. Marwa, 2009. Effect of Prophetic medicine Kalonji (Nigellasativa L.) on Lipid profile of human beings: AnIn Vivo Approach. World Applied Sciences Journal 6(8): 1053-1057.

Bintvihok, A. and S. Kositcharoenkul, 2006.Effect of dietary calcium propionate on performance, hepatic enzyme activities and aflatoxin residues in broilers fed a diet containing low levels of aflatoxin B1. Toxicon. 47: 41-46.

Bintvihok, A.; W. Banlunara, and T. Kaewamatawong, 2002. Aflatoxin detoxification by esterified glucomannan in ducklings. Thai J. Health Res. 16: 135-148.
Bintvihok, A., D. Uaphua, P. Klainil, R. Intraraksa, S. Sutherat, K. Wisutharom, M. Boonmeerod, and M. Hayashi. 1991. Aflatoxin and toxic residue: its influence with regard to jeopardize the chicken and tissues. $J$. Thai Vet. Med. Assoc. 42: 209-217.

Council for Agriculture, Science and Technology. 2003. Mycotoxins: Risks in Plant, Animal and Human Systems. In: CAST Task force report No. 139. Ames, Iowa, USA,.

Cavin, C., M. Marin-Kuan, S. Langouet, C. Bezencon, G. Guignard, C. Verguet, D. Piguet, D. Holzhauser, R. Cornaz, and B. Schilter. 2008. Induction of Nrf2mediated cellular defenses and alteration of phase I activities as mechanisms of chemoprotective effects of coffee in the liver. Food and Chemical Toxicology 46: $1239-1248$.

Choudhary, A. and R. J. Verma. 2005.Ameliorative effects of black tea extract on aflatoxin-induced lipid peroxidation in the liver of mice. Food and Chemical Toxicology 43: 99-104.

Citil, M., V. Gunes, O. Atakisi, A. Ozcan, M. Tuzcu, and A. Dogan. 2005. Protective effect of L-carnitine against oxidative damage caused by experimental chronic aflatoxicosis in quail (Coturnixcoturnix). Acta Vet. Hung. 53(3): 319-324.

Coles, E,H. 1974. Veterinary clinical pathology. Saunders Company, Phladelphia and London,

Criseo, G. A. Bagnara, and G. Bisignano, 2001. Differentiation of aflatoxin-producing and nonproducing strains of Aspergillusflavus group. Letters in Applied Microbiology 33(4):291.

Culling, C. F, 1983 Handbook of Histopathological and Histochemical Staining Techniques. $3^{\text {rd }}$ ed. Butterworth-London.

Donma, M. and O. Donma, 2007. Hair zinc, aflatoxin and malnutrition. Med Hypotheses. 68(2): 461-462.

El-Far, A., H.2003.Biochemical alterations induced by administration of lead in rabbits and the protective role of Nigella sativa (black seed), master thesis. Fac. Vet. Med., Alex. Univ.,

El-Gazzar, M.; R. El-Mezayen, R. Mark, R. Nicolls, R. John, C. Marecki, C. Stephen, and C. Dreskin, 2006. Downregulation of leukotriene biosynthesis by thymoquinone attenuates airway inflammation in a mouse model of allergic asthma, Biochim.Biophys. Acta. 1760: 1088-1095.

Fossati, P. and L. Prencipe. 1982.Serum triacylglycerols determined colorimetrically with an enzyme that produces hydrogen peroxide. Clin Chem. 28(10): 20772080.

Guerre, P., G. Larrieu, V. Burgat, and P. Galtier, 1999. Cytochrome $\mathrm{P} 450$ decreases are correlated to increased microsomal oxidative damage in rabbit liver and primary cultures of rabbit hepatocytes exposed to AFB1. Toxicol. Lett. 104(1-2): 117-125. 
Habig, W. B.; M.J. Pabst, and W. B. Jakoby,. 1974. Glutathione-S-transferases: The first enzymatic step in mercapturic acid formation. J. Biol. Chem. 249: 7130-7139.

Han, X., Y.; Q. Huang, W. Li, J. Jiang, Z. Xu, 2008. Changes in growth performance, digestive enzyme activities and nutrient digestibility of cherry valley ducks in response to aflatoxin B1 levels. Livestock Science 119(1/3):216-220.

Henry R.J.1964. “Clinical chemistry”. $1^{\text {st }}$ Ed. Harper \& Row Publishers, New York P. 181, Coles, E, H.: Veterinary clinical pathology. Saunders Company, Phladelphia and London.

Hosseinzadeh, H., S. Parvardeh, M. Aslb, H. Sadeghnia, and T. Ziaeec, 2007.Effect of thymoquinone and Nigella sativa seeds oil on lipid peroxidation level during global cerebral ischemia-reperfusion injury in rat hippocampus. Phytomedicine 14: 621-627.

Jackson, P., E. and J.D. Groopman, 1999. Aflatoxin and liver cancer. Bailliere's Best Pract. Res. Clin. Gastroenterology 13(4): 545-555.

Karaman, M., H. Ozen, M. Tuzcu, Y. Cigremis, F. Onder, and K. Ozcan, 2010.Pathological, biochemical and haematological investigations on the protective effect of alpha-lipoic acid in experimental aflatoxintoxicosis in chicks, Br Poult Sci.; 51(1): 132-41.

Le, P., M., B. Ali, E. Aziz, S. Abdellatif, C. Yahia, and S.H Pierre. 2004. The petroleum ether extract of Nigella sativa exerts lipid-lowering and insulinsensitizing actions in the rat. Journal of Ethnopharmacology 94(2-3): 251-259.

Madden, U., A. and H. M. Stahr. 1995. Retention and distribution of aflatoxin in tissues of chicks fed aflatoxin-contaminated poultry rations amended with soil. Vet Hum Toxicol. 37(1): 24- 29.
Madheswaran, R., C. Balachandran, C. Murali, and B. Manohar. 2004. Influence of dietary culture material containing aflatoxin and T2 toxin on certain serum biochemical constituents in Japanese quail. Mycopathologia 158(3): 337-341.

Maraqa, A., N.F. Al- sharo, H. Farah, W. M. Elbjeirami, A.K. Shakya and A. Sallal, 2007. Effect of Nigella sativa Extract and Oil on Aflatoxin Production by Aspergillusflavus J. Turk. J. Biol. 31: 155-159.

Placer, Z., A. L. Crushman, and B.C. Johnson. 1966. Estimation of product of lipid peroxidation (malodialdhyde) in biochemical systems. Anal. Biochem. 16: 359-364.

Reitman, S. and S. Frankel, 1957.A colorimetric method for the determination of serum glutamic oxalacetic and glutamic pyruvic transaminases. Amer. J. Clin. Pathol. 28: 56-63.

Salem, M., L. and M.S. Hossain, 2000. Protective effect of Black seed oil from Nigella sativa against Murine cytomegalovirus. Int. Immunopharmacol. 22 (9): 729-740.

SAS: Statistical Analysis System, 1996. Users Guide Statistics, SAS Institute Cary, North Carolina.

Sedlak, J. and R. H. Lindsay, 1968. Estimation of total, protein-bound, and nonprotein sulfhydryl groups in tissue with Ellman's reagent. Anal. Biochem. 25(1): 192-205.

Shotwell, O., L.; C.W. Hessltine, R. D. Stubblefiehd, and W.G. Sorenon, 1966. production of aflatoxin on rice. Applied microbiology 14(3): 425-428.

Toulah, F. H.2007.Effect of aflatoxin on the coccidial infection in broilers.J. Egypt. Soc. Parasitol. 37(3):785-92.

Zak, B.; R.C. Dickenman, E. G. White, H. Burnett, and P.J. Cherney, 1954.Rapid estimation of free and total cholesterol. Am J ClinPathol. 24(11): 1307-1315. 
Nepal Journal of Science and Technology Vol. 14, No. 1 (2013) 81-90 